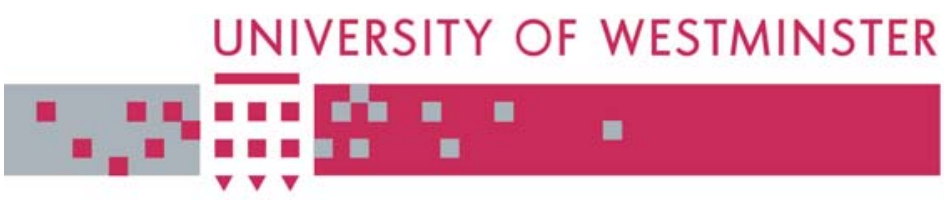

\title{
WestminsterResearch
}

http://www.wmin.ac.uk/westminsterresearch

\section{Waveguide resonators in planar form for oscillator and filter applications.}

\section{Healias Koulouzis \\ Laleh Lalehparvar \\ Djuradj Budimir}

School of Informatics

Copyright ( 0 [2003] IEEE. Reprinted from the proceedings of the 11th IEEE International Symposium on Electron Devices for Microwave and Optoelectronic Applications, 2003. EDMO 2003, pp. 71-75.

This material is posted here with permission of the IEEE. Such permission of the IEEE does not in any way imply IEEE endorsement of any of the University of Westminster's products or services. Internal or personal use of this material is permitted. However, permission to reprint/republish this material for advertising or promotional purposes or for creating new collective works for resale or redistribution must be obtained from the IEEE by writing to pubs-permissions@ieee.org. By choosing to view this document, you agree to all provisions of the copyright laws protecting it.

The WestminsterResearch online digital archive at the University of Westminster aims to make the research output of the University available to a wider audience. Copyright and Moral Rights remain with the authors and/or copyright owners.

Users are permitted to download and/or print one copy for non-commercial private study or research. Further distribution and any use of material from within this archive for profit-making enterprises or for commercial gain is strictly forbidden.

Whilst further distribution of specific materials from within this archive is forbidden, you may freely distribute the URL of the University of Westminster Eprints (http://www.wmin.ac.uk/westminsterresearch). 


\title{
Waveguide Resonators in Planar Form for Oscillator and Filter Applications
}

\author{
H.: Koulouzis, L. Lalehparvar and D. Budimir \\ Wireless Communications Research Group, Department of Electronic Systems, \\ University of Westminster, London, W1W 6UW, UK \\ Tel: +44 207 91 15139; Fax: +44 207 9115089; Email: d.budimir(awmin.ac.uk
}

\begin{abstract}
In this paper a new direct integration of rectangular waveguide with planar circuits on the same substrate is presented. Since the design of such structure is very complex, first the substrate integrated rectangular waveguide is converted to an equivalent rectangular waveguide, so that the well-established rectangular waveguide design theory can be applied. Periodic resonator at $3.5 \mathrm{GHz}$ and $28 \mathrm{GHz}$ is designed, simulated, fabricated and tested. This resonator structure is then used for filter and oscillator applications. Bandpass filter and oscillator at $28 \mathrm{GHz}$ are designed and simulated. The proposed technique shows promising features such as reduced size, reduced cost and more compact resonator and filter structures, while maintaining easy fabrication process.
\end{abstract}

\section{Introduction}

Rectangular waveguide components are widely used at microwave and $\mathrm{mm}$-wave frequencies. They can be used to design high $Q$ components, but their difficult integration and high cost prevent them to be used in low-cost high volume applications [1]. Therefore a new design technique is proposed, where the rectangular waveguide and the planar circuits are integrated on the same substrate. Here the sidewalls of the rectangular waveguide are realized within the substrate, using array of metallic vias. The ground plane of the microstrip line becomes one metallic wall of the waveguide, while the tapered microstrip line provides the other metallic wall. Rectangular waveguide supports theTE 10 mode so the tapered microstrip lines connected to the input and output ports act as mode converters, transforming the microstrip modal energy into the waveguide and vice versa. Another advantage of this scheme is that, its guided wave characteristics are similar to those of conventional rectangular waveguide with equivalent width. Therefore by knowing its equivalent width, we can apply the existing design techniques of rectangular waveguides for the analysis and design of the structures based on this new scheme. This is a great advantage, since the analysis and design of this planar structure is much more complex than the conventional rectangular waveguide. Also the simulation of the substrate integrated rectangular waveguides using FEM method requires abundant resources, so they can be first converted to conventional rectangular waveguide in order to approximate its physical dimensions and electromagnetic behaviour and then commercial FEM package can used for their optimization. Also the periodic configuration, which is used for the resonator design, offers more compact structures, which is of great importance at high frequencies. The proposed design technique is well suited in the design of mm-wave circuits such as resonators, filters, oscillators and antennas.... etc.

\section{Proposed Configurations}

To show the applicability of the proposed waveguide resonators in planar form, this section demonstrates an application in filters and oscillators development. Periodically loaded resonator at 3.5 $\mathrm{GHz}$ and $28 \mathrm{GHz}$ are designed, simulated, fabricated and tested. As shown in Fig.1, the periodic resonator and the transition are integrated on the same substrate. The metallic strips, which are used to present the discontinuity, are transversely inserted inside the waveguide. This is a very compact 
structure and still maintains simple fabrication process. The resonator is designed and the structure is simulated using commercial FEM software package HFSS ${ }^{\mathrm{TM}}$. The results are then confirmed by experiments. The resonator is constructed on $0.254 \mathrm{~mm}$ thick RT5880/Duroid substrate with $\varepsilon_{\mathrm{r}}=2.22$. The waveguide has a width $\mathrm{a}=6.096 \mathrm{~mm}$ and length $1=16 \mathrm{~mm}$. The walls in the E-plane are constructed with 0.8 via-hole arrays. The spacing between two adjacent vias is also 0.8 . Metallic strips all have width of $0.5 \mathrm{~mm}$, height of $0.254 \mathrm{~mm}$ and are all $0.5 \mathrm{~mm}$ thick. The length of the resonator is $3.8 \mathrm{~mm}$, which is chosen to be approximately half the guide wavelength $(\lambda \mathrm{g} / 2)$. Further more a bandpass filter and an oscillator are designed at $28 \mathrm{GHz}$ based on this new periodic structure with the planar transition. The filter consists of 2 resonator sections each having a length of $4 \mathrm{~mm}$. The dimensions of the rectangular waveguide, vias and discontinuities are the same as the designed resonator at $28 \mathrm{GHz}$.

\section{Simulated and Experimental Results}

To verify the proposed concept, direct integration of the periodic rectangular waveguide resonators and the planar transitions at $3.5 \mathrm{GHz}$ and $28 \mathrm{GHz}$ are designed, simulated, fabricated and measured. The circuits are designed and fabricated on a $1.524 \mathrm{~mm}$ and $0.254 \mathrm{~mm}$-thick RT5880/Duroid dielectric substrate with $\varepsilon_{\mathrm{r}}=2.22$. In order to measure the resonator, microstrip transitions are designed as described in [2]. Corresponding simulated and measured responses of the resonator at $3.5 \mathrm{GHz}$ are presented on Fig. 2 and 3 respectively. Resonator, bandpass filter and oscillator based on the proposed periodic structure and the planar transition are also designed and simulated at $28 \mathrm{GHz}$. Commercial software package HFSS ${ }^{\text {TM }}$ is used for the simulation of these structures. Corresponding S-parameter responses are presented in Fig. 4 , and 5 for the $28 \mathrm{GHz}$ resonator and bandpass filter respectively. Fig.6. shows the simulated responses of the oscillator. The photograph of the fabricated waveguide resonator at $28 \mathrm{GHz}$ is shown in Figure 7.

\section{Conclusion}

Rectangular waveguide resonator structures in planar form for filter and oscillator applications have been presented. It allows a complete planar integration of these structures without any mechanical assembly. The proposed integration technique results in reduced size, compact and easy fabrication technique that is well suited for microwave and mm-wave circuit components such as, resonator, filters, oscillators and antenna, ...etc. Based on the proposed configuration, a periodic resonator, bandpass filter and an oscillator at $28 \mathrm{GHZ}$ were designed, and simulated. In order to demonstrate the proposed planar technique, a resonator at $3.5 \mathrm{GHz}$ is designed, fabricated and measured.

\section{Acknowledgement}

This work was supported by the Engineering and Physical Science Research Council (EPSRC), United Kingdom

\section{References}

[1] D. Deslandes and K. Wu, "Integrated microstrip and rectangular waveguide in palanar form"

IEEE Microwave and wireless component Letters, vol. 11, No. 2, Febuary 2001

[2] Y. Cassivi, D. Deslandes, K. Wu, " Low-cost and high-Q mm-wave resonator using substrate integrated waveguide technique" in proc. Eur. Microwave Conf., 2002.

[3] C.-k. C. Tzuang, and al., "H-plane mode conversion and application in printed microwave integrated circuit" in proc. Eur. Microwave Conf., vol. 2, Oct. 200, pp. 37-40.2002.

[4] D. Budimir and C. Turner, "Novel high-Q waveguide E-plane resonators using periodic metallic sept", Microwave and Optical Technology Letters, vol. 23, no. 5, December 1999, pp. 311-312 
[5] Y. Cassivi, L. Perregrini, p. Arcioni, M. Bressan, K.Wu, and G. Conciauro, "Dispersion characteristics of substrate integrated rectangular waveguide" IEEE Microwave and wireless component Letters, vol. 12, no. 9, September 2002.

[6] Y. Cassivi and $\mathrm{K}$. Wu, "Low Cost Microwave Oscillator Using Substrate Integrated Waveguide Cavity", IEEE Microwave and Wireless Components Letters, Vol. 13, No. 2, February 2003.

[7] P. G. Wilson and R. D. Carver, "An easy-to-use FET DRO design procedure suited to most CAD programmes", IEEE, MTT-S Internation Microwave Symposium Digest, pp. 10331036,1989

[8] Ansoft HFSS Ver. 8.5., CA, USA, 2003.

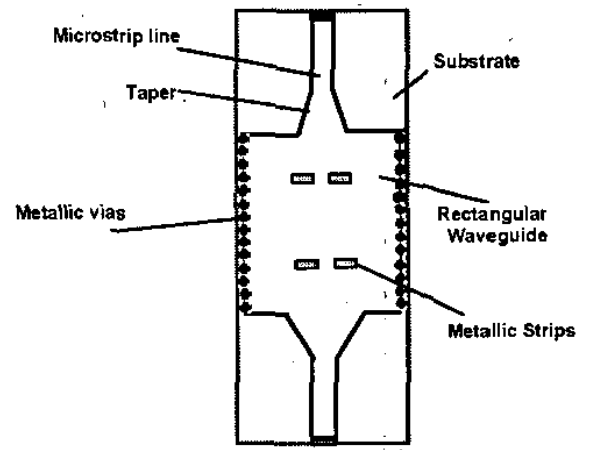

Fig. 1. Configuration of the proposed periodic resonator structure and the planar transition of microstrip line to rectangular waveguide on the same substrate.

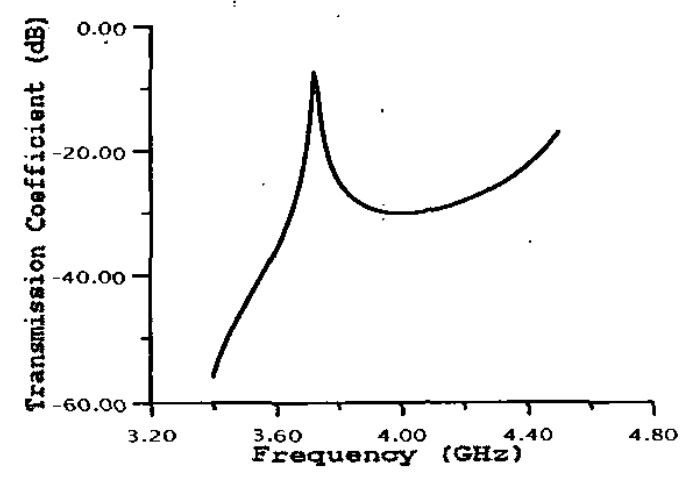

Fig. 2. Simulated response of the periodic resonator structure with planar waveguide-to-microstrip transition at $3.5 \mathrm{GHz}$. 


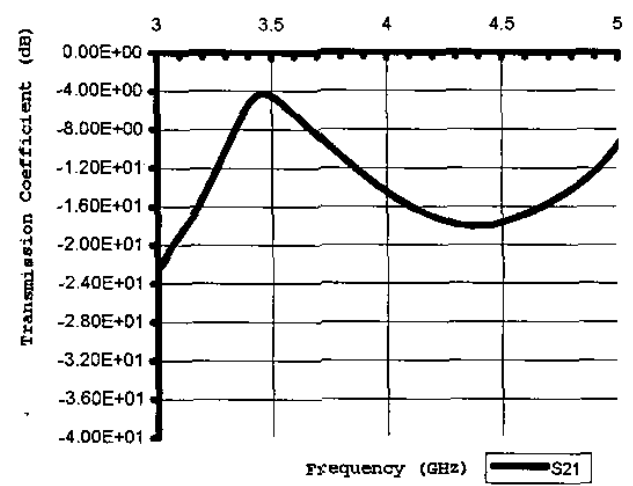

Fig. 3. Measured response of the periodic resonator structure with planar waveguide-to-microstrip transition at $3.5 \mathrm{GHz}$.

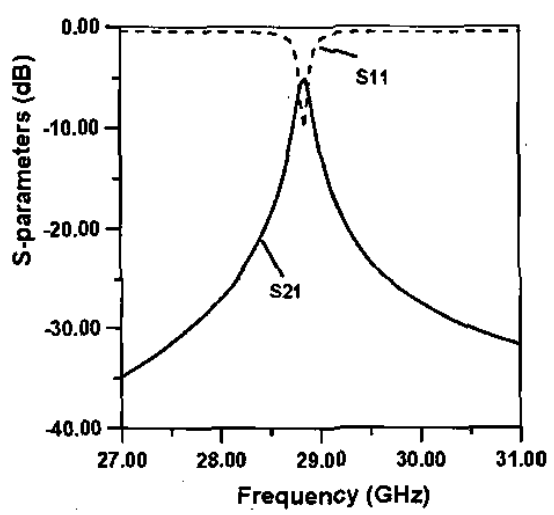

Fig. 4. Simulated response of the periodic resonator structure with planar waveguide-to-microstrip transition at $28 \mathrm{GHZ}$.

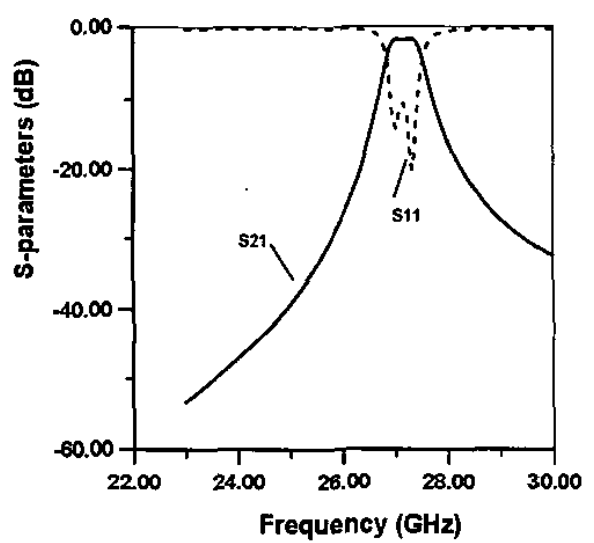

Fig. 5. Simulated response of the periodic filter structure with planar waveguide-to-microstrip transition at $28 \mathrm{GHz}$. 


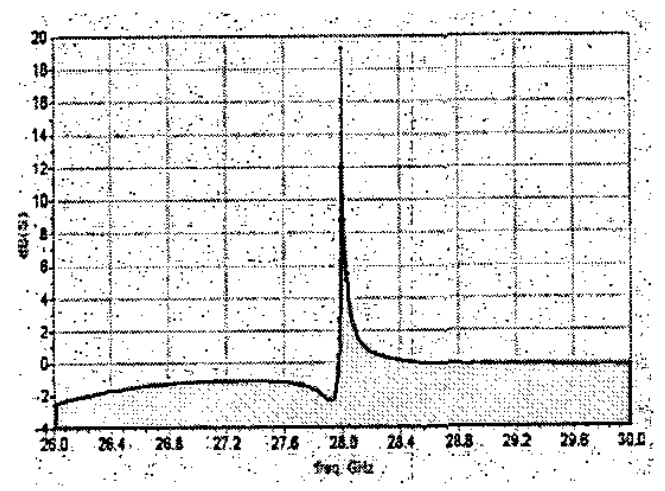

Fig. 6. Simulated response of the oscillator at $28 \mathrm{GHz}$.

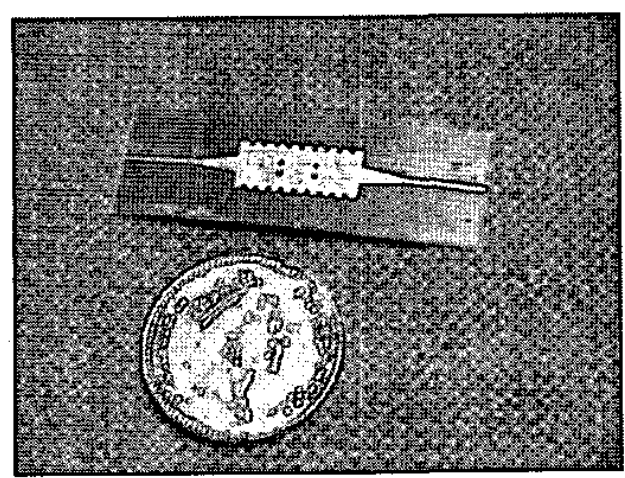

Fig. 7. Photograph of the fabricated periodic resonator with microstrip transition. 